\title{
Diaphragmatic Injuries, A Retrospective Analysis of 50 Patients
}

\author{
A BILAL MSALIM $^{*}$ T NISHTAR ${ }^{* *}$ MSNABI $^{*}$ M. MUSLIM* ${ }^{*}$ MAHMED GALI ${ }^{* * *}$ S S CHEEMA \\ * Department of Cardiothoracic Surgery, Postgraduate Medical Institute, Peshawar \\ ** Department of Radiology, Postgraduate Medical Institute, Peshawar \\ *** Department of Anaesthesia, Postgraduate Medical Institute, Peshawar \\ Correspondence to Dr. Amer Bilal, Associate Professor
}

\begin{abstract}
Objective:: This study seeks to define the clinical presentation, the usefulness of diagnostic tests, surgical management approach and outcome of treatment of diaphragmatic injuries in our trauma patients. Design:: An observational descriptive study. Place and duration of study:: Department of Cardiothoracic Surgery, Postgraduate Medical Institute, Lady Reading Hospital, Peshawar from March 2001 to April 2005. Subjects and methods: In this retrospective study, 50 patients admitted to our department with diaphragmatic injury were evaluated according to the type of injury, diagnostic methods, associated organ injury, treatment, modality, morbidity and mortality. Results: The average age of patients was 32 years. There were $35(70 \%)$ male and $15(30 \% 0$ female patients, $38(76 \%)$ of these patients sustained blunt and $12(24 \%)$ had penetrating chest injury. The diaphragmatic injury was right sided in 4 and left sided in 46 patients. Thirty nine (78\%) patients presented in respiratory distress within 48 hours of injury while $11(22 \%)$ presented with bowel obstructive symptoms months and years after injury. A chest x-ray on admission suggested the diagnosis in $70 \%$ of the cases while chest ultrasonography and contrast studies were required in others. Surgery was emergent in $35(70 \%)$, semi-emergent in 9 $(18 \%)$ and effective in $6(12 \%)$ cases. Surgical approaches were left thoracotomy (40 patients), left thoracolaprotomy (6 patients) and right thoracotomy (4 patients). The diaphragmatic repair was achieved by direct suture in 45 cases while prolene Mesh was required in 5 cases. The mortality rate was $6 \%(n=3)$. Recurrence occurred in one $(2 \%)$, wound infection in $3(6 \%)$, pleural, space, problem in 1 and chest infection in $2(4 \%)$ patients. Conclusion: A high index of suspicion and early surgical treatment determine the successful management of traumatic diaphragmatic injury with or without the herniation of abdominal organs. The surgical approach is individualized. We prefer the thoracic approach adding laporotomy when necessary.
\end{abstract}

Key words: Diaphragm, Injury, Management

The first traumatic diaphragmatic hernia was reported in 1579 by Pare who described the postmortem finding in two patients who died after or blunt injury and gunshot wound respectively.' In this report Pare described an autopsy done on an artillery captain who died of strangulated intestinal obstruction after incarceration of the intestine through a traumatic laceration of the diaphragmatic sustained 8 months earlier ${ }^{2}$. Naumann in 1888 operated on a patient who had a traumatic diaphragmatic hernia and in whom the stomach had herniated into the left side of the chest. Traumatic diaphragmatic hernias are produced by either blunt thoraco-abdominal trauma or penetrating wounds of the diaphragm. Traumatic diaphragmatic hernia due to blunt trauma is thought to be produced by sudden increase in the pleuro-peritoneal pressure gradient ${ }^{3}$. Automobile accidents are the most common cause of blunt traumatic diaphragmatic hernias and in most series approximately $90 \%$ involve the left hemidiaphragm. Defects are large usually between $10 \mathrm{~cm}$ and $15 \mathrm{~cm}$ and are located in the posterior aspect of left hemidiaphragm ${ }^{4}$. Respiratory insufficiency due to compressed lung and shift of mediastinum are common in early phase of injury whereas symptoms of chronic intestinal obstruction are more common when the hernia has' been present for considerable time ${ }^{5}$.

The diagnosis of diaphragmatic rupture can be elusive. The chest film is still the best initial screening examination and the absence of complete visualization of the entire hemidiaphragm and abdominal high position of the stomach should raise an index of suspicion of injury. ${ }^{6}$ Sonography, diaphragmatic screening may also contribute to the diagnosis while barium studies of the intestine or colon are often helpful in diagnosis of chronic hernias?

If the defect is recognized acutely repair should be undertaken. Right sided hernias are difficult to repair through an abdominal incision because of the presence of the the liver. After intraabdominal reduction of herniated viscera, a single layer closure of interrupted nonabsorbable sutures have been used successfully ${ }^{8}$. Chronic hernias can be managed electively unless they present with signs of acute intestinal obstruction. The thoracic approach allows better access to multiple adhesions that often involve the intestine and the pulmonary parenchyma. Primary repair of the diaphragm is usually possible but prosthetic patches can be employed when necessary?.

The mortality associated with diaphragmatic injury varies between 10 and $15 \%$. This is largely due to associated injuries but is occasionally a consequence of complications from missed injury during laparotomy ${ }^{10}$.

This study was aimed to observe the clinical presentations of diaphragmatic injury to validate the surgical technique employed and determine the outcome.

\section{Patients and methods:}

This is a retrospective analysis of patients operated for diaphragmatic injuries between March 2001 and April 2005. Records of fifty patients who were subjected to operation were included in this study. Computerized 
hospital records and operation notes of these patients were carefully analysed for demographic features, choice of procedure and outcome.

\section{Operative technique:}

The operation is performed on right or left $7^{\text {th }}$ space postero-lateral thoracotomy with or without laparotomy extension depending upon the site and extent of injury. Once the pleural space is entered, assessment of the extent of diaphragmatic injury, herniated viscera and pulmonary parenchyma was made. Any adhesions between lung and herniated abdominal viscera were divided. The diaphragmatic margins were defined. Herniated abdominal organs were gently reduced down to abdomen, obtaining clear visibility of diaphragmatic margins. In few cases conversion of thoracotomy incision to thoracolaparotomy aided in reducing the herniated viscera. The need for prolene mesh graft was determined by the extent of diaphragmatic tear specially the integrity of costal fibers. Direct primary closure was done without tension on suture line. Repair was accomplished by direct suture using double layer of non-absorbable suture. In patients with large defect, repaired was achieved using prolene mesh graft. The pleural cavity was evacuated through a chest drain. Serial post-operative radiographs were obtained to ascertain the integrity of hemidiaphragm. The patients were discharged on $8^{\text {th }}$ or $9^{\text {th }}$ postop day.

\section{Results:}

Out of 50 patients, there were $35(70 \%)$ male and $15(30 \%)$ female patients. The type of injury was blunt in $38(76 \%)$ while $12(24 \%)$ had penetrating chest injury. The diaphragmatic injury was right sided in $4(8 \%)$ and left sided in $46(92 \%)$ patients (Table 1$)$

The clinical presentation varied according to time of injury and arrival. Respiratory distress was the most common presentation in $39(78 \%)$ patients who presented in 48 hours of injury while $11(22 \%)$ patients presented with signs of intestinal obstruction months and years after injury. On physical examination bowel sounds were noted over the involved side of the chest.

The chest radiograph suggested the diagnosis in 35 $(70 \%)$ of the cases while chest ultrasonography; diaphragmatic screening and contrast studies were required in others. Surgery was emergent in $35(70 \%)$, semiemergent in $9(18 \%)$ and elective in $6(12 \%)$ cases. The surgical approaches were left thoracotomy in $40(80 \%)$; left thoracolaparotomy in $6(12 \%)$ and right thoracotomy in 4 (8\%) patients. The diaphragmatic repair was achieved by direct suture in $45(90 \%)$. While prolene mesh was required in $5(10 \%)$ (Table 2). Two adult patients also required splenectomy for severe laceration (Table-3). The mortality rate in our series was $6 \%(3 / 50)$. The complications included recurrence $1(2 \%)$, wound infection $3(6 \%)$, pleural space problems $1(2 \%)$ and chest infection in $2(4 \%)$ cases.
Table 1: Preoperative Date $(\mathrm{n}=50)$

\begin{tabular}{lll}
\hline Variables & $=\mathrm{n}$ & \%age \\
\hline Sex & & \\
Male & 25 & 70 \\
Female & 15 & 30 \\
Type of injury & & \\
Blunt & 38 & 76 \\
Penetrating & 12 & 24 \\
Side & & \\
Left & 46 & 92 \\
Right & 04 & 8 \\
Symptoms & & \\
Respiratory distress & 39 & 78 \\
Signs of intestinal obstruction & 11 & 22 \\
Investigations & & \\
X-ray chest (diagnostic sensitivity) & 35 & 70 \\
\hline
\end{tabular}

Table 2: Diaphragmatic repair $(n=50)$

\begin{tabular}{lll}
\hline Variables & Size & \%age \\
\hline Timing & 35 & 70 \\
Emergent & 09 & 18 \\
Semi emergent & 06 & 12 \\
Elective & & \\
Approach & 40 & 80 \\
Left thoracotomy & 06 & 12 \\
Left thoracolaparotomy & 04 & 08 \\
Right thoracotomy & & \\
Technique & 45 & 90 \\
Direct closure & 05 & 10 \\
Prolene mesh & & \\
\hline
\end{tabular}

Table 3: Mortality and morbidity (n-50)

\begin{tabular}{lll}
\hline Variables & $=\mathrm{n}$ & \%age \\
\hline Deaths & 03 & 06 \\
Complications & & \\
Rccurrence & 01 & 02 \\
Pleural space problems & 01 & 02 \\
Chest infection & 02 & 04 \\
Wound infection & 03 & 06 \\
\hline
\end{tabular}

\section{Discussion:}

Diaphragmatic injury may result from penetrating or blunt trauma to this musculotendineous structure that separates the thoracic and abdominal cavities ${ }^{11}$. If laceration is not recognized and promptly repaired, one or more of abdominal viscera will herniate into the thoracic cavity, with resultant compromise of ventilatory or gastrointestinal function ${ }^{2,12}$. Immediate herniation is most often associated with a large tear while small rents such as those caused by stab wounds are rarely symptomatic early; however if unrepaired progressive abdominal visceral herniation occurs because of pressure gradient between thoracic and peritoneal cavities ${ }^{13,17}$. The rupture most commonly occurs in the left leaf; however the right hemidiaphragm is not immure from injury. Various studies have shown rupture of the left hemidiaphragm in $68 \%$, the right in $24 \%$ and bilateral in $1.5 \%^{4,14}$. In our study, left sided injury was in $92 \%$ and right sided injury in $8 \%$ cases. Moreover, blunt injury was the predominant type of injury 
(76\%). Symptoms and signs of diaphragmatic rupture depend on the type; extent, associated injuries and time interval between injury and presentation ${ }^{15}$. The diaphragmatic rupture itself may cause a degree of respiratory distress as the hemithorax accumulates effusion or is compromised with bowel contents.

The timely diagnosis of diaphragmatic injury presents a diagnostic challenge. Routine radiography of the chest is the most required study. It is abnormal in almost all blunt injury patients and is diagnostic in over half of the patients. Traumatic hernias are frequently misdiagnosed as loculated hydropneumothorax leading to the erroneous use of chest tubes. The sensitivity of x-ray chest is reported $86 \%$ in presence of visceral herniation and $14 \%$ in absence of visceral hernia ${ }^{3,16}$. In our study, the diagnostic sensitivity of chest $x$-ray was $70 \%$. The abnormality may include an area of radiolucency, one or more air fluid levels in the lung field, with or without mediastinal shift. Ultrasonography, contrast studies and computed tomography may be helpful, but probably less so in the evaluation of patients thought to have acute injury of the diaphragm $^{9,17}$.

Because of the danger of development of respiratory or even circulatory compromise or visceral obstruction with incarceration or strangulation, diaphragmatic injury should be repaired surgically as soon as possible when the patient's clinical condition permits ${ }^{5,18}$. In our series, $70 \%$ of the patients underwent emergent exploration.

Although the diaphragmatic leaf may be best exposed through the chest, the approach chosen should be based on the clinical finding in each patient. Tears of the left hemidiaphragm are most often repaired through the abdomen because of frequently associated injuries to intraabdominal organs although in the absence of any symptoms suggesting such injury a left thoracotomy is adequate. Tears of the right hemidiaphragm when recognized are best approached through a right thoracotomy. The diaphragmatic defect can be closed primarily in majority of the patients. Prosthetic material is rarely needed in acute blunt trauma injuries. Our observation of direct closure of the tear in $90 \%$ of cases is in line with other studies ${ }^{19,20,6}$.

The initial injury to the diaphragm from either blunt or penetrating trauma may be undetected during the patient's first hospitalization and may only become manifest because of symptoms and signs related to a hernia of one or more abdominal viscera into the chest. Although no large body data is available it is most likely that more late diaphragmatic hernias result from missed stab wound injuries than from blunt trauma $a^{6,10}$.

These hernias may be recognized any time from a few weeks to over three or four decades after original injury. The diaphragmatic injury may be missed in the absence of other indications for prompt surgery where a thorough examination of both hemidiaphragms in mandatory. A high index of suspicion combined with repeated and selective radiologic evaluation is necessary for early diagnosis. ${ }^{9,21,22}$

The mortality may be high in blunt diaphragmatic injuries, not as the result of diaphragmatic injury perse but as the consequence of other severe visceral trauma. Various studies have reported $22 \%$ mortality in this group of patients whereas $2.2 \%$ mortality have been reported for penetrating injury. 8,23 The mortality after repair of a diaphragmatic hernia that was recognized late varies greatly depending on the status of the hernia at the time of its repair. In patients, who present late with a strangulated, gangrenous viscus in the hernia the mortality may be as high as $80 \%$. These missed hernias, therefore must be recognized and repaired, before obstruction and gangrene of the contained visceral segment occur. ${ }^{3,6,24}$

\section{Conclusion:}

1. Careful clinical examination coupled with an accurate interpretation of the Roentegenograms should detect most cases of traumatic rupture of the diaphragm.

2. Impairment of respiratory function, possibility of strangulation and incarceration of the abdominal viscera demand early repair.

3. The choice of incision and approach depends on the stage at which the rupture is recognized (early or late), the site of rupture and the associated injuries.

4. Careful assessment of respiratory function should be made in order to prevent post-operative complications; in some cases respiration must be assisted.

5. lthough the mortality in patients with traumatic diaphragmatic rupture is still relatively high, the deaths should not be related to the rupture per se, or to its repair but rather to the associated injuries.

\section{References:}

1. Ivatury RR. The role of laproscopy in establishing diaphragmatic injury in lower chest wonds. J Trauma 2005 Jun; 58(6): 1305.

2. Healy DG, Veerasingam D, Luke D, Wood EA. Delayed discovery of diaphragmatic injury after blunt trauma : report of three cases. Surg Today 2005; 35(5): 407- 10.

3. Van Colen S, Shannon C. Images in medicine. Remote diaphragmatic injury during radiofrequency ablation: efficacy of intraabdominal cardbon dioxide insufflation. AJR Am J Reontgenol 2004 Jul; 183(1): 197- 200.

4. Lee DI, Clayman RV. Use of gelatin matrix to rapidly repair diaphragmatic injury during laparoscopy. Urology 2004 Feb;63(2): 419

5. Iochum S, Ludig T, Walter F, Sebbag H, Grosdidier G, Blum AG. Imaging of diaphragmatic injury: a diagnostic challenge? Radiographics, 2002 Oct; 22 Spec No: S103 -16.

6. Adler DH. Blunt diaphragmatic injury in a 7-year-old girl. J Emerg Med. 2002 Jul; 23(1): 39- 42.

7. Larici AR, Gotway MB, Litt HI, Reddy GP, Webb WR et al. Helical CT with sagittal and coronal reconstructions: accuracy for detection of diaphragmatic injury. AJR Am J Reontgenol 2002 Aug; 179(2): 451 - 7.

8. Gonzalez CM, Batler RA, Feldman M, Rubenstein JN, Nadler RB et al. Repair of a diaphragmatic injury during had 
assisted laparoscopic nephrectomy using an onlay patch of polypropylene and polyglacin mesh. J Urol 2002 Jun; 167(6): $2512-3$.

9. Karmy Jones R, Carter Y, Stern E. The impact of positive pressure ventilation on the diagnosis of traumatic diaphragmatic injury. Am Surg 2002 Feb; 68(2): 167 - 72.

10. Abdel Hadi Ms, Al-Muhim AA, Al-Awad NI, Zakaria H, Al-Awami MS. Diaphragmatic injury. A clinical review. Saudi Med J. 2001 Oct;22(10): $890-4$.

11. Potter SR, Kavoussi LR, Jackman SV. Management of diaphragmatic injury during laparoscopic nephrectomy. J Urol 2001 Apr; 165(4): 1203-4.

12. Sacchi M, Di Gaetano G, Del Giudice M, Ricci F, Apa D et al. Traumatic diaphragmatic injuries. Chir Ital 2000 SepOct; 52(5): 499-503.

13. Koplewitz BZ, Ramos C, Manson DE, Babyn PS, Ein SH. Traumatic diaphragmatic injuries in infants and children: imaging findings. Pediatr Radiol $2000 \mathrm{Jul}$; 30(7):471-9.

14. Shanmuganathan $\mathrm{K}$, Killeen $\mathrm{K}$, Mirvis SE, White CS. Imaging of diaphragmatic injuries. J Thorac Imaging 2000 Apr; 15(2): 104-11.

15. Gibbons JR, McGuigan J. Delayed infarction of the stomach following diaphragmatic injury. Injury 1997 Nov -Dec; 28(9-10): 690-2.
16. Road JD, Jiang TX. Determines of diaphragmatic injury. Mil Cell Biochem. 1998 Feb;179(1-2): 81-6.

17. Bagree MM, Gupta HP, Poonia IP, Saran RK. Diaphragmatic injuries in civilian practice. J Indian Med Assoc. 1998 Jan; 96(1):27-8.

18. Reber PU, Schmied B, Seiler CA, Baer HU, Patel AG, Buchler MW. Missed diaphragmatic injuries and their longterm sequelae. J Trauma 1998 Jan; 44(1): 183-8.

19. Shackleton KL, Stewart ET, Taylor AJ. Traumatic diaphragmatic injuries: spectrum of radiographic findings. Radiographs 1998 Jan-Feb;18(1): 49-59.

20. Lindsey I, Woods SD, Nottle PD. Laparoscopic management of blunt diaphragmatic injury. Aust Z J Surg. 1997 Sep;67(9):619-21.

21. Arak T, Solheim K, Pillgram-Larsen J. Diaphragmatic injuries. Injury $1997 \mathrm{Mar}$; 28(2): 113-7.

22. Kang EY, Muller NL. CT in blunt chest trauma: pulmonary, tracheobronchial and diaphragmatic injuries. Semin Ultrasound CT MR. 1996 Apr; 17(2): 114-8.

23. Spann JC, Nwariaku FE, Wait M. Evaluation of videoassisted thoracoscopic surgery in the diagnosis of diaphragmatic injuries. Am J Surg 1995 Dec; 170(6): 628.

24. Guth AA, Pachter HL, Kim U. Pitfalls in the diagnosis of blunt diaphragmatic injury. Am J Surg 1995 Jul; 170(1):5-9. 